\title{
Vocabulary in learning processes towards conceptual understanding of equivalent fractions-specifying students' language demands on the basis of lexical trace analyses
}

\author{
Lena Wessel ${ }^{1}$
}

Received: 20 June 2018 / Revised: 18 July 2019 / Accepted: 7 August 2019 /

Published online: 28 November 2019

(C) The Author(s) 2019

\begin{abstract}
Although the teaching of vocabulary in mathematics lessons is requested in contentand language-integrated lesson designs, the clarification of the specific lexical language demands is still an open question for many mathematical topics. In a content- and language-integrated lesson design towards understanding the concept of equivalent fractions, the vocabulary (words and phrases) used by 17 students has been analyzed with qualitative means of data analysis. The qualitative in-depth analyses underline the importance of meaning-related vocabulary for making structural relations between the fractions in view explicit. Quantitative analyses of inventoried vocabulary for the four categories "self-initiated by students," "triggered by teaching material," "triggered by teacher," or "triggered by peers" show the relations of collective and autonomous vocabularies from which the students retrieve their lexical means in oral and written language production.
\end{abstract}

Keywords School academic language · Design research · Equivalent fractions · Trace analysis

\section{Introduction}

More than 30 years ago, Orton (1987) already claimed that "it might be that problems of vocabulary are considered to be fairly superficial within the whole issue of language and mathematics learning, but it is nevertheless critical that such problems are not ignored in the hope they will go away" (p. 127). This is even more important due to the cognitive and epistemic function of language in general and of the language of

Lena Wessel

lena.wessel@ph-freiburg.de

1 University of Education Freiburg, Kunzenweg 21, 79117 Freiburg, Germany 
schooling in particular, which can be challenging for many students (Schleppegrell 2004). These challenges are relevant with respect to all school subjects, including mathematics (OECD 2007), as well as in multilingual contexts (Planas and Civil 2013).

However, the systematic specification of topic-specific language demands still remains a major goal that has yet to be realized. On the lexical level, this relates to the required key vocabulary for the different mathematical topics in order to better understand and define the topic-specific school academic-language demands. This study makes a contribution towards this goal in the mathematical topic of equivalent fractions. The learning processes from an overarching content- and language-integrated intervention study are investigated in order to understand the role and use of vocabulary in students' learning processes towards understanding equivalent fractions. More specifically, the vocabulary offered in the teaching material and the activated lexical means of the students are inventoried and analyzed qualitatively in relation to the individual conceptual learning pathways towards equivalent fractions. Thus, this paper contributes to the important overall research question (to be refined in the "Equivalent fractions: mental models, representations, and registers" section): Which lexical demands appear and how are they interrelated with processes of developing conceptual understanding of equivalent fractions?

To approach this overall research question, the theoretical and empirical background on language in mathematics is introduced in the "Theoretical background: school academic language" section with a focus on vocabulary teaching and learning. The theoretical background for the field of fractions and related aspects of language are sketched in the "Equivalent fractions: mental models, representations, and registers" section. The "Research context and design" section outlines the research context and the methodology of the study. The "Students' use of vocabulary along conceptual learning pathways" section presents selected results of the qualitative (the "Specifying students' language demands on the basis of lexical trace analyses" section) and quantitative (the "Quantitative comparisons of self-initiated and triggered vocabulary" section) analyses, while the "Discussion" section relates and discusses the empirical findings with respect to their implications and methodological restrictions.

\section{Theoretical background: school academic language}

In this section, the theoretical background with respect to language and its challenges in mathematical learning processes is presented. A focus is put on the teaching and learning of vocabulary in mathematics and the research aims in this field.

\section{School academic language in mathematics teaching and learning}

In some countries, researchers have investigated the mathematics achievement gap between students with diverse language backgrounds for more than 25 years (Secada 1992), and the attention to language gaps is currently increasing (OECD 2007; Haag et al. 2013). In the German context, a variety of large-scale studies have replicated the language gap for mathematics achievement (Heinze et al. 2009; Prediger et al. 2015b). More precisely, research has shown that many students with low language proficiency encounter other serious obstacles beyond reading challenges, especially when high 
conceptual demands are required (Ufer et al. 2013). That is why, in addition to the communicative role of language, its epistemic role in processes of knowledge construction as a medium of thinking (Heller and Morek 2015; Vygotsky 1978) also has to be taken into account. As a consequence, mathematics education researchers' and mathematics teachers' awareness that "the chief cause of the achievement gap between socio-economic groups is a language gap" (Hirsch 2003, p. 22)-more precisely a school academic-language gap-constantly increases.

Bailey (2007) summarizes academic-language proficiency as the knowing and being able to:

use general and content-specific vocabulary, specialized or complex grammatical structures, and multifarious language functions and discourse structures-all for the purpose of acquiring new knowledge and skills, interacting about a topic, or imparting information to others.

(Bailey 2007, p. 10). Here, a differentiation is made not only between the communicative and epistemic role of (academic) language but also (1) between a rather general academic-language proficiency needed across different subjects and the specific academic language needed for a particular subject, and (2) between the different features of academic language on the lexical, syntactical, and discursive levels. These levels are also used by other linguists to characterize the general differences between everyday language and school academic language (e.g., on the lexical level, by specialized vocabulary, composite or unfamiliar words, and specific connectors; on the syntactical level, by long and syntactically complex sentences, passive voice constructions, and long noun phrases and prepositional phrases; and on the discursive level, by specific discursive practices such as arguing or explaining why; Bailey 2007; Heller and Morek 2015).

So far, many studies have compared the mathematics performance of (a) students who speak the language of instruction as a second language (in English studies often referred to as English language learners (ELL)) with the performance of proficient speakers of the language of instruction or (b) monolingual with multilingual students (for an overview, see Haag et al. 2013). Though their results are not fully consistent, the studies suggest that "descriptive, lexical, and grammatical features of test items may influence the performance of second language learners" (ibid., p. 26). Of course, monolingual students and students with the language of instruction as their first language are also academic-language learners. Thus, in this study, we speak of language learners, which refer not only to second-language learners but to all students with low academic-language proficiency in the language of instruction (Planas and Civil 2013, for politically mediated tensions in multilingual settings of mathematics teaching and learning).

\section{School academic language on the lexical level and its relation to discourse}

Lexical learning aims at extending the students' individual mental lexicons. A mental lexicon functions as a mental web of vocabulary, which constantly changes when new 
lexical means, their meanings, and information on spelling, pronunciation, or usage in phrases are added (Aitchison 2003). To develop understanding of a mathematical concept, of course, in addition to acquiring words and phrases, students need to construct the meaning of the concept (semantic area) and learn for which problems and purposes it is applied (pragmatic area; Schleppegrell 2004). Together, these are the facets that make up conceptual understanding of a mathematical concept, which is operationalized as mental models (Prediger 2008) and involves the construction of new mental objects and relationships (Steinbring 2005) in contrast to technical, procedural skills that can be carried out without deeper understanding.

In research contributions on academic language, the relevance of lexical means is often discussed in relation to the discursive level of academic language, while the latter is regarded to be more important and more challenging than the former. Relying on the seminal work by Halliday (1978), O'Halloran (2015) subsumes that "the difficulty of scientific language is the larger theoretical framework within which technical terms are defined and the metaphorical nature of the discourse of argumentation in which these terms are used, rather than individual terms themselves" (p. 65). With respect to designing classroom activities, Moschkovich also concludes that we need to think of "how instruction can best support students to learn vocabulary as they actively engage in mathematical reasoning about important mathematical topics" (Moschkovich 2013, p. 46f).

On the other hand, there is empirical evidence indicating that for meeting discursive demands, students need particular lexical means. Quasthoff (2012) distinguishes more demanding discourse practices such as "explaining" or "arguing" from less demanding ones such as "reporting" or "describing." She characterizes the first kind as lexically more demanding because more elaborated lexical means are needed in order to make connections and conclusions explicit. There is also empirical evidence that the development of discourse competence is related to a differentiated mental lexicon (see Grundler 2009). Analyses of small-group discussions indicate that oral and written argumentative units of discourse are strongly related to the vocabulary of students. For her analyses, the author classifies (ibid., p. 85) students' self-initiated lexical means as autonomous vocabulary; in contrast, the collective vocabulary is established by teaching material or previous lexical means in the local discourse under investigation. By inventorying the autonomous and collective vocabulary on the basis of transcripts, the author observed that a high level of autonomous vocabulary goes along with complex lines of argumentation. In argumentative settings, students with a high level of autonomous vocabulary have been identified as those speakers who stand out, since they put forward the argument (ibid., p. 91).

One instructional approach for implementing vocabulary teaching in rich discursive settings is the Sheltered Instruction Observation Protocol (SIOP) (Short 2017). The SIOP model suggests teaching strategies such as the use of concept definition maps, word banks, sentence starters, and sentence frames (for an overview of strategies, see Fisher and Frey 2008; Donelly and Roe 2010; Riccomini et al. 2015). However, there has been limited research that focuses specifically on interventions such as these vocabulary teaching strategies and their effects on developing vocabulary in mathematics (Riccomini et al. 2015, p. 247) or, more importantly for mathematics educators, on developing an understanding of mathematical concepts. 
To implement lexical teaching strategies, it is crucial to know what exactly constitutes the key vocabulary for a specific mathematical topic. Potential rather general pitfalls of the mathematical register have been well described theoretically for both English (e.g., overview in O'Halloran 2015; Thompson and Rubenstein 2000; Pimm 1987) and German (see Niederhaus et al. 2016). For the German language, connectors such as prepositional phrases or conjunctions have been identified as crucial for mathematical learning, especially for developing a conceptual understanding (Prediger and Zindel 2017). One explanation for this phenomenon draws upon the specifics of mathematics: "The grammatical patterning of mathematics often presents processes as if they were things by construing them as nouns and noun phrases" (Schleppegrell 2007, p.146). To unfold the processes and ideas encapsulated in noun phrases, prepositions, and more complex sentence structures are often needed (see Prediger 2011a, for the case of the preposition "out of" (German "von")). It has to be acknowledged though that this research has been carried out for English and German, each with a specific grammar relying on the use of prepositions. Different results are expected for other languages which, for example, rely on case marking. In any case, topic-specific empirical research that specifies key vocabulary needed for developing conceptual understanding is still required for many topics (exceptions Pöhler and Prediger 2015, for percentages; Prediger and Zindel 2017, for functions).

\section{Equivalent fractions: mental models, representations, and registers}

In the following section, equivalent fractions as the mathematical topic under investigation is outlined (the "Mental models of equivalent fractions" section). An additional focus is put on relating registers and representations as theoretical background and core design principle for the design of the learning opportunities (the "Representations and registers for understanding mathematical concepts" section), which are presented in the "Learning opportunities towards understanding equivalent fractions and typical student challenges" section.

\section{Mental models of equivalent fractions}

The development of conceptual understanding is a central goal of mathematics instruction (for the different strands of mathematical competence, see Kilpatrick et al. 2001). Fractions were chosen as the specific mathematical topic for the larger intervention since fractions are one of the most difficult topics in the middle school curriculum, especially if the aim is developing a conceptual understanding (Aksu 1997). The latter is encapsulated in the construct of rational number sense:

Students who have developed rational number sense have an intuitive feel for the relative sizes of rational numbers and the ability to estimate, to think qualitatively and multiplicatively, to solve proportions and to solve problems, to move flexibly between interpretations and representations, to make sense, and to make sound decisions and reasonable judgments. 
(Lamon 2007, p. 636). To understand and reason the equivalence of fractions, the structural understanding of relating two fractions is crucial (Prediger 2013). In addition, Lamon (2007) reveals critical components that underlie multiplicative thinking, especially relative thinking, unitizing, reasoning up and down, sharing, and comparing, as well as norming. These aspects are important when specifying the relevant mental models of equivalent fractions in different representations and interpretations of fractions (for the construct of mental models see Prediger 2008):

- In part-whole interpretations, equivalent fractions are found by thinking of the parts and wholes in terms of larger or smaller chunks. To develop conceptual understanding, context situations involving sharing are often applied, e.g., "A cake is cut in different ways, 3 out of 4 equal pieces is as much cake as _ out of $8(12,16, \ldots)$ equal pieces?" Here, the comparison of two fractions relies on the mental model "as much as," e.g., "3 out of 4 equal pieces is as much as 6 out of 8 equal pieces." This mental model draws upon the critical components unitizing and reasoning up and down.

- Beyond the part-whole interpretation, the concept of ratio (a relationship between a pair of quantities) is fundamental to fractions (Lamon 2007). Comparisons of ratio and rates, for example in contexts of sports competitions, serve to develop conceptual understanding of equivalent fractions (Prediger 2013). Here, a comparison relies on the mental model "as good as," e.g., a rate of 3 goals out of 4 attempts is as good as a rate of 6 goals out of 8 attempts. This mental model draws upon the critical components relative thinking and reasoning up and down.

- To interpret equivalent fractions in a graphical representation, a structural understanding and the critical components of unitizing and norming are important. In fraction bars of equal length, equivalent fractions are found by vertical comparison (see Fig. 1). Fractions for which the colored part in the bar is equally long are equivalent. An explanation for this equivalence relies on the mental models of refining and coarsening ${ }^{1}$ which can be developed when the structure of both fraction bars is related to each other. From $6 / 8$ to $3 / 4$, the fraction is simplified, but the fraction bar structure is coarsened: Every two pieces in the bar of eighths become one piece in the bar of fourths while the colored part stays the same. From 6/8 to $12 / 16$ the fraction bar structure is refined: Every piece in the bar of eighths is divided by two and thus becomes two pieces in the bar of sixteenths while the colored part stays the same ("as long as").

\section{Representations and registers for understanding mathematical concepts}

Due to the specific ontological nature of mathematical objects as abstract and mostly relational entities, a mathematical concept such as fraction cannot be understood just by referring to real objects. This is why mathematics educators (Duval 2006; Lesh 1979; Clarkson 2009) and psychologists (Bruner 1967) have emphasized the importance of

\footnotetext{
${ }^{1}$ The German verb vergröbern is translated with the verb "coarsen." It is being used for lack of a suitable English word. Literally, vergröbern means "to make sth more roughly."
} 

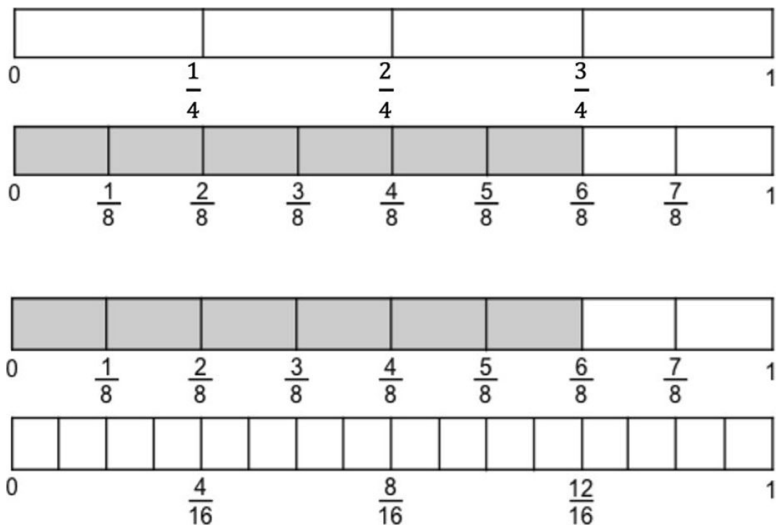

Fig. 1 Equivalent fractions in graphical representation

multiple representations. By transitioning between verbal, symbolic, graphical, and concrete representations, students can construct the mental objects and relations to which a mathematical concept refers (Lesh 1979; Cramer et al. 1997).

For the theoretical underpinning of the construct of registers, this study draws on Halliday's definition of the register as "set of meanings, the configuration of semantic patterns, that are typically drawn upon under the specific conditions, along with the words and structures" (Halliday 1978, p. 23). He emphasizes the social embeddedness: "A register can be defined as the configuration of semantic resources that a member of a culture typically associates with the situation type ... in a given social context" (ibid., p. 111). Hence, for Halliday, registers are characterized by the types of communication situations, their field of language use, the discourse styles, and modes of discourse. Drawing on Halliday's theory, O'Halloran (2015) develops a multimodal approach to the mathematics register (as a multimodal register) in which language operates in conjunction with symbolism and visual representations to create meanings. By doing so, she extends the understanding of language by also taking into account functions and grammatical features of graphical representations (in her wording "images") and mathematical symbolism. Duval (2006) also gives different mathematical representations a status of different "semiotic registers" and emphasizes that the meaning of a mathematical object can change with a shift in representation. In a social semiotic perspective, both can be subsumed as registers and the relating registers and representations approach was proven as a fruitful design strategy for integrating language and mathematics learning (Clarkson 2009; Prediger and Wessel 2013).

Coming back to the different registers of language, namely everyday, academic, and technical registers (see the "Theoretical background: school academic language" section), empirical research implies that the language registers themselves need to be refined, because the registers do not grasp the mathematics-specific subtleties sufficiently: Based upon their theoretical and textbook analyses, Prediger and Zindel (2017, p. 4163), in their study for dealing with word problems in the field of functions, specify "explaining the meaning of concepts" as the most important discursive language demands in the development of conceptual understanding. To meet this discursive demand, very specific lexical means, in the following subsumed in the basic meaning-related 
vocabulary, is needed. These are words and phrases that grasp mathematical relations and meanings (e.g., "take away" that is often used in situations of subtraction) which mostly belong to the academic school register (Pöhler and Prediger 2015; Wessel 2015). Examples are given in Table 1 for the part-whole interpretation of and operations with fractions.

In contrast, formal vocabulary is specified in mathematics curricula and textbooks. The formal vocabulary, as part of the more technical register, is often specified as an explicit learning goal. From an empirical research perspective, it is not yet clear how students acquire relevant vocabulary and how this relates to their mathematical learning. A case study by Zahner et al. (2012) relates mathematical learning gains of students to the vocabulary introduced by three teachers in a mathematics lesson on functions. For these analyses, the vocabulary was analyzed in-depth and students' learning gains were measured with a curriculum-aligned assessment. The lesson in view was conceptually focused, and all three teachers used a similar set of terminologies. Two of the three teachers, whose students had relatively high gains, "both used informal language as a resource to introduce an important concept and then used the formal vocabulary term after the idea had been introduced into the discussion" (ibid., p. 438). In contrast, the third teacher, who was less successful in promoting students' learning, "supplied the formal terminology in talk that appeared less carefully structured to bridge informal and formal ways of reasoning" (ibid., p. 438). The authors conclude "that learning conceptually demanding mathematics requires more than being exposed to technical vocabulary" (ibid., p. 438). Due to the small sample of three teachers and classrooms, these findings of course have to be interpreted carefully. Still, the findings indicate the need for topic-specific empirical research on lexical demands in learning processes towards understanding a certain mathematical concept.

Table 1 Refined model of representations and registers with sample representations and vocabulary.

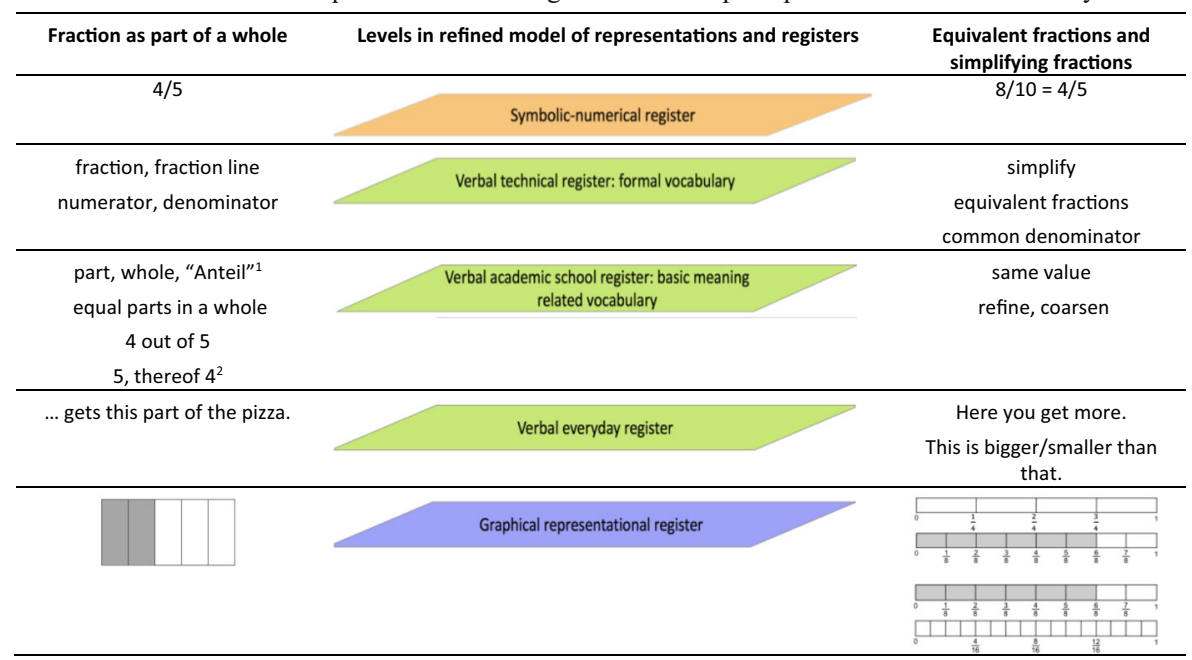




\section{Learning opportunities towards understanding equivalent fractions and typical student challenges}

The overarching intervention is based on the design principles of providing rich opportunities for language production, scaffolding, and the principle of relating registers and representations (for an overview see Schüler-Meyer et al. 2019). The intended conceptual learning opportunities towards understanding equivalent fractions (see Wessel 2017) have been adapted from previous design research (Prediger 2013; Prediger and Wessel 2013) and start with students' individual approaches and everyday experiences in comparing scored goals for an unequal number of attempts in a competitive situation.

In Task 1 (see Fig. 2), three fictitious groups with different numbers of attempts and scored goals in the context of a soccer competition are introduced. It then proceeds to constructing a meaning of the given data by introducing the fraction bar board (see Fig. 2, Task 2) which the students already know from the previous intervention lesson to represent fractions, so that they are already familiar with it at this point. The graphical representation is used to support the development of mental models of equivalence (see the "Mental models of equivalent fractions" section). Task 2 aims at elaborating students' informal comparison strategies by focusing on the need for normed referent wholes (here fraction bars of normed length) and the necessity of including every group's number of attempts (not only the number of scored goals).

According to previous research on fraction comparison strategies initiated by a similar task (Prediger 2011b), students' first informal comparison strategy is often an absolute comparison with a focus only on the absolute number of scored goals. Accounting for the total number of attempts is a necessary step towards multiplicative comparison, for which "comparing with the

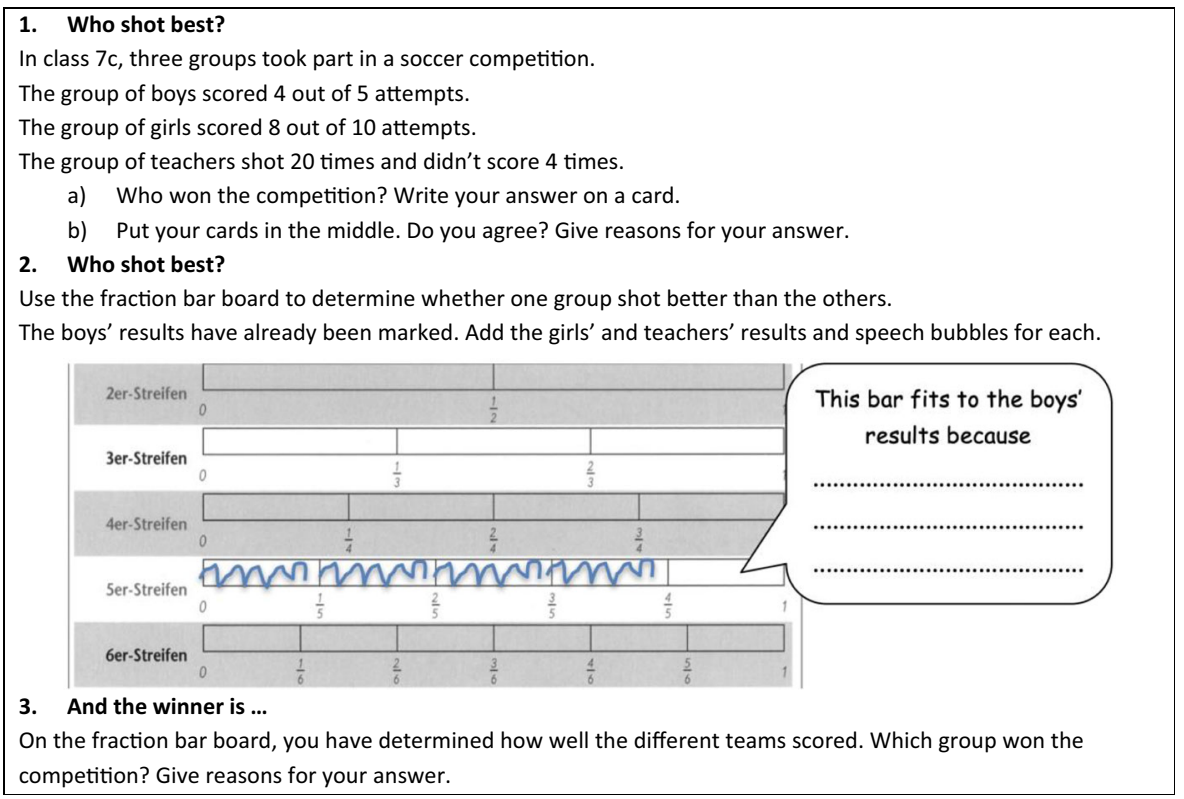

Fig. 2 Learning opportunities towards understanding equivalent fractions translated from German to English (except for original German labels of fraction bars) and shortened (full fraction bar board includes fraction bars up to bars of twentieths) 
fraction bar board" is a sustainable sample strategy (other sustainable multiplicative strategies are for example "comparing with one half" or "reasoning up and down," cf. ibid.). Of course, there is an ambiguity in the task's question "who shot best" about what "best" means in this context. This is one reason why an absolute comparison is also an interpretation of the question that is reasonable in a real-world sense.

Intended to initiate elaboration of the fraction bar comparison strategy, Task 2 aims at developing a structural understanding of the given rates and corresponding fractions bars. Structural understanding can become visible in processes of structural reasoning which is differentiated from empirical reasoning. Empirical reasoning denotes coming to a conclusion on the basis of empirical observations of representations or a small number of examples without attending to an underlying, explaining structure (see Schwarzkopf 2003, p. 231; Steinbring 1994; see also the taxonomy of proof by Balacheff 1988). Structural reasoning can also rest upon representations, concrete numbers, and examples, but they function to explain a more general finding in a more generic reasoning. Schwarzkopf (2003) describes this as a structural view behind the empirically found phenomenon (also see Moschkovich 2015 for the practice "attending to structure"). Prediger's case studies (2011c; 2013) revealed that the conceptually relevant step towards structural understanding and reasoning can be challenging for students: "especially weaker students tend not to construct the mathematically intended structural relations automatically" (Prediger 2013, p. 343), so that these processes need more explicit support. This is one reason why, after the collaborative work and discussions in Task 2, students in Task 3 are individually asked to fulfill the discursive demand of giving reasons when writing down their answers to the question of "which group wins."

\section{Research questions}

On the basis of the theoretical background and the research aims listed above, the empirical analyses of the learning processes initiated by the learning opportunities towards understanding equivalent fractions are guided by the following research questions:

Q1. Which task- or concept-specific lexical means do students use along the learning pathway and how do they relate to the development of conceptual understanding of equivalent fractions?

Q2. To what extent do students self-initiate or take up lexical means from teaching materials, the teacher, or peers in local processes initiated by the presented learning opportunities?

\section{Research context and design}

In this section, methods for data collection and the sampling procedure for data analysis are presented. The data analysis is based on the approach of lexical trace analysis by Pöhler and Prediger (2015). Its modification for this study's research focus is presented in the "Qualitative and quantitative methods for data analysis" section. 


\section{Design experiments as a method for data collection and sampling decisions}

The research was conducted using a mixed-methods design in which topic-specific didactical design research and a quantitative intervention study are combined. Design experiments are considered the methodological core of design research studies as they allow in-depth investigations of learning processes rather than only learning outcomes (Cobb et al. 2003; Gravemeijer and Cobb 2006). They serve as a means of data gathering for the qualitative in-depth analyses of conceptual and lexical learning processes (Prediger et al. 2015a).

The design experiments were conducted and videotaped within the larger research project Mesut $^{2}$ with $N=186$ mathematically low-achieving students, aged 13 to 15 , from comprehensive schools in North Rhine-Westphalia, Germany. The setting was small-group teaching (with 3-6 students per group, in total 38 groups taught by 16 teachers, who were either research team members or students in their final year of studies in a master program of mathematics education). All teachers took part in a 2-day training on the basic design principles, lesson plans, and task activities. The training consisted of video vignette analyses and collection of teaching experience with the teaching material in role plays.

For the qualitative in-depth analysis, six student groups (taught by four different teachers) have been selected according to students' German academic-language proficiency (measured with a German C-test; Prediger and Wessel 2013) and language background (mono- or multilingual, operationalized by "speaks at least one language other than German with a parent or grandparent") as well as richness of the initiated learning processes. The sampling aimed at a linguistically heterogeneous sub-sample to conduct case analyses and contrast different language backgrounds. The quantitative analysis draws upon the qualitative in-depth analysis (see "Qualitative and quantitative methods for data analysis" section).

\section{Qualitative and quantitative methods for data analysis}

To explore research questions Q1 and Q2, the six teacher-moderated small groups' learning processes have been transcribed for the following learning opportunities and video data:

- The learning opportunities towards understanding equivalent fractions (from the second lesson of the overarching intervention, tasks presented in the "Equivalent fractions: mental models, representations, and registers" section): 113 min of video data displaying work of $n=16$ students. The qualitative in-depth case studies discussed in the "Students' use of vocabulary along conceptual learning pathways" section draw upon this data.

- Selected learning opportunities towards the part-whole interpretation of fraction (from the first lesson of the overarching intervention, see Prediger and Wessel (2013) for detailed description of task): 176 min of video data displaying work of $n=17$ students (one student did not pursue taking part in the intervention after the first lesson).

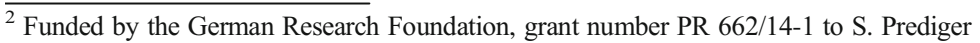


In total, 298 min of video data have been transcribed for carrying out the following steps of analysis and which relate to the research questions as follows:

Step 1: Conceptual analysis To analyze students' conceptual development, taskspecific categories have been applied that relate to Task 1 and Task 2 of the learning opportunities (see Fig. 2). Previous research by Prediger (2011b) provided comparison strategies (absolute and multiplicative) and mental models for fraction equivalence (as much as, as good as, as long as) which both serve as theoretically based categories for deductive conceptual analysis.

Step 2: Trace analysis The methodological basis for identifying and contrasting lexical learning pathways builds a modification of the trace analysis developed by Prediger and Pöhler (2015, p. 1187). This analytical tool allows inventorying and tracing the students' lexical means in three steps.

Preparation for Steps 2a and 2b Based on all transcripts and conceptual analyses, two consolidated corpora of relevant lexical means (i.e., words and phrases; see appendix Table 8 for the equivalent fractions corpus) have been defined for the actual trace analyses for each of the two analyzed learning opportunities. The lexical means have been assigned to be included in the consolidated corpora by two researchers, who came to their decision after discussing the importance of a specific lexical mean for modeling and elaborating on the given situation in the task, and expressing important individual ideas related to conceptual understanding.

Step 2a In line with Prediger and Pöhler (2015), those lexical means (words and phrases) of the consolidated corpus are inventoried along the tasks and transcripts. For this purpose, trace analysis tables (see Fig. 3) are used. Lexical means from the consolidated corpus are highlighted in the transcript and coded in the corresponding trace analysis tables according to Step $2 b$ with one column for teacher and teaching material and one column for each student involved in the transcribed learning process. The completed trace analysis tables allow for keeping track of the micro-processes of students, teacher, and teaching material introducing and taking up lexical means (see the next step and Fig. 3).

Step $2 \mathbf{b}$ The inventoried lexical means are coded in the trace analysis table for the mode in which they are used (black print for oral, gray print for written use). The inventoried lexical means in Fig. 3 are all in black print, indicating that the inventoried vocabulary is used orally. Moreover, inventoried lexical means are coded for their trigger which indicates by whom and in which mode (oral or written $(\mathrm{o} / \mathrm{w})$ ) a lexical mean was used just before the moment of usage in view:

- Students self-initiate lexical means, indicated with (si) (which is in line with Prediger and Pöhler (2015) who used "teacher-initiated" as complement category), or

- Students take up lexical means from either the teaching material (indicated with $\mathrm{TM}$ ), the teacher (T), or other peers in the group (indicated by the first letter of students' name). 


\begin{tabular}{|c|c|c|c|c|}
\hline & $\begin{array}{l}\text { Example: } \\
\text { Turn 56: Teacher (T) uses } \\
\text { "fits" orally. } \\
\text { Trigger: T39 where } \\
\text { Teaching Material (TM) } \\
\text { introduced "fits" in written } \\
\text { mode (T39, TM, w). }\end{array}$ & $\begin{array}{l}\text { Example: } \\
\text { Turn 58: Makbule uses } \\
\text { "because" orally. } \\
\text { Trigger: T57 where } \\
\text { Vehbiya (V) used } \\
\text { "because" orally (T57, V, } \\
\text { o). }\end{array}$ & $\begin{array}{l}\text { Example: } \\
\text { Turn 57: Vehbiya uses } \\
\text { "because" orally. } \\
\text { Trigger: T39 where } \\
\text { Teaching Material (TM) } \\
\text { introduced "because" in } \\
\text { written mode (T39, TM, } \\
\text { w). }\end{array}$ & $\begin{array}{l}\text { Example: } \\
\text { Turn 60: Kiran uses } \\
\text { "fraction" orally. } \\
\text { Trigger: T60 where Kiran } \\
\text { self-initiates "fraction" } \\
\text { orally (T60, si, o). }\end{array}$ \\
\hline Turn & $\begin{array}{l}\text { Teacher }(\mathrm{T}) \text { or } \\
\text { Teaching Material (TM) }\end{array}$ & Makbule (M) & Vehbiya (V) & Kiran (K) \\
\hline 56 & $\begin{array}{l}\text { fits (passt zu) (T39, TM, } \\
\text { w) } \\
\text { fraction bar (Bruchstreifen) } \\
(\mathrm{T} 39, \mathrm{TM}, \mathrm{w})\end{array}$ & & & \\
\hline 57 & & & $\begin{array}{l}\text { because (weil) (T39, TM, } \\
\text { w) }\end{array}$ & \\
\hline 58 & & $\begin{array}{l}\text { because (weil) }(\mathrm{T} 57, \mathrm{~V}, \mathrm{o}) \\
\text { had ... attempts }(\ldots \text { Schuss } \\
\text { gehabt) (T25, si, o) } \\
\text { scored ... times (... mal } \\
\text { getroffen) (T25, si, o ) }\end{array}$ & & \\
\hline 59 & $\begin{array}{l}\text { fraction bar (Bruchstreifen) } \\
(\mathrm{T} 56, \mathrm{~T}, \mathrm{o})\end{array}$ & & & \\
\hline 60 & & & & fraction $($ Bruch $)(T 60, \mathrm{si}, \mathrm{o})$ \\
\hline 61 & & because (weil) (T58, si, o) & & \\
\hline
\end{tabular}

Fig. 3 Example of trace analysis table for a sample transcript (see the "Specifying students' language demands on the basis of lexical trace analyses" section for transcript). The turn numbers in the far-left column refer to the transcript lines.

The set of information "when," "by whom," and "mode" can be found in the trace analysis table in brackets for each inventoried lexical mean (see Fig. 3 and examples for each column at the top).

Step 2c The results of Steps $2 \mathrm{a}$ and $2 \mathrm{~b}$ form the database for an overall quantitative analysis for exploring research question Q2. For this purpose, numbers of inventoried lexical means are compared with expected numbers of lexical means in a chi-square test. This allows for interpreting and comparing the rates of the four coded categories (self-initiated vocabulary and vocabulary triggered by teaching material, teacher, or peers) in written and oral use. The database for this quantitative analysis comprises all transcribed video data (lexical trace analysis for 298 min of video data).

Accounting the self-initiated vocabulary as autonomous vocabulary and the vocabulary triggered by teaching material, teacher, or peers as part of the collective vocabulary (see the "School academic language on the lexical level and its relation to discourse" section) enables an analysis of the relation of autonomous and collective vocabulary. Of course, such an approach has its limitations: autonomous vocabulary relates to vocabulary as self-initiated in these specific local processes which are confined by the selected tasks. This implies that a student might have used a specific lexical mean in other situations beforehand (e.g., for data from the second lesson, in the first lesson). With this method of analysis, it is zoomed into specific excerpts of the interaction. Only for these specific excerpts, vocabulary is coded as selfinitiated or triggered. Conversely, we blend out hypothetical previous processes of self-initiation which could have taken place before the analyzed learning 
process in view starts. Being aware of this limitation and interpretation, this method still provides insights into how students' vocabulary is triggered in this very local perspective.

\section{Students' use of vocabulary along conceptual learning pathways}

In this section, the research questions Q1 and Q2 are explored. While qualitative analyses are carried out to approach Q1 in the "Specifying students' language demands on the basis of lexical trace analyses" section for equivalent fractions (see the "Qualitative and quantitative methods for data analysis" section for database), the "Quantitative comparisons of self-initiated and triggered vocabulary" section draws upon the lexical trace analyses of data from two lessons and presents a quantitative view at the data.

\section{Specifying students' language demands on the basis of lexical trace analyses}

In this section, the focus is put on research question Q1 Which task-or concept-specific lexical means do students use along the learning pathway and how do they relate to the development of conceptual understanding towards equivalent fractions? By presenting selected moments and cases from the in-depth qualitative analyses, conclusions are drawn for an empirically informed specification of lexical means that have been evaluated as a key vocabulary for

- developing conceptual understanding of equivalent fractions in teaching designs that draw upon activities of relating registers, and

- meeting the discursive demand of structural reasoning why two rates (consequently two fractions) are equivalent.

For this purpose, the presented case studies already combine results of conceptual and trace analyses. In an intertwined way, key steps on the conceptual learning pathway are related to the identified lexical demands.

\section{The case of Kiran introducing the "thereof" preposition for making part-whole relations explicit}

In the analyzed data set, absolute and multiplicative comparison strategies have been identified. For overcoming absolute comparison strategies, the importance of the meaning-related prepositional phrases "_ out of _" (part stated first, whole stated second) and "_ thereof _" (whole stated first, part stated second) as relevant lexical means for relating parts and wholes had already become visible in previous case studies (Wessel 2017).

While the teaching material introduces the prepositional "_ out of _" construction in Task 1, in all six analyzed groups, the "_ thereof " construction was also introduced by the students. For the presented case of Group X, it is Kiran who introduces this expression. The relevant excerpt of the learning process has been chosen 
for discussion because for this group, the trace analysis reveals that the other students in the group adopt the expression.

Kiran (multilingual, high language proficiency) works together with Makbule and Vehbiya. The excerpt in Table 2 shows how-when working on Task 2 of the learning opportunities - an argumentative unit of discourse is initiated by reflecting on why the chosen fraction bar of fifths fits the results of the boys (initiated by the teacher in Turn 56).

In Turn 67, Kiran self-initiates the prepositional phrase from his autonomous vocabulary. The use of this phrase is part of Kirans's answer to the teacher repeatedly asking "why does the fraction bar fit?" (Turns 56 and 59). Again, in Turn 63 the teacher asks the students to agree on one justification. So far, several explanations came up: "Because they [the boys] took five shots and have only scored four times" (Makbule in Turn 56 and again interrupted in Turn 64), "Because it's four fifths" (Makbule, Turn 61 ), "In the fraction, it would be four fifths" (Kiran, Turn 60/62), "Because they [the boys] scored four goals" (Vehbiya, Turn 64).

Though the previous utterances of Makbule (Turn 64) and Vehbiya (Turn 66) refer to the context situation, namely the number of attempts ("they had five") and scored goals ("they scored four goals"), their structural relation is not yet made explicit. Kiran (maybe assuming that the teacher is not yet satisfied with their arguments) lexically introduces a way for relating the number of attempts and number of scored goals more explicitly and precisely. To do so, he introduces the prepositional phrase "five shots and thereof only scored four" into the group's collective vocabulary (in addition to the prepositional phrase introduced by the material). This phrase is identified as key vocabulary on the conceptual learning pathway because it puts emphasis on the total number of attempts. Linguistically, this emphasis is obtained by putting the whole (here: number of attempts) at the beginning of the phrase.

How Kiran's peers take up the prepositional phrase "_ thereof _" in the following learning process (in written as well as oral mode) is shown in Table 3 for the case of

Table 2 Episode with Makbule (M), Kiran (K), Vehbiya (V), and Teacher (T): Kiran (K) introduces "thereof" construction.

\begin{tabular}{lll}
\hline Turn & Person & Utterances and gestures (translation from German to English; "//" indicates interruptions) \\
\hline 56 & $\mathrm{~T}$ & So why does this fraction bar frt the boys, the one that is marked there? \\
57 & $\mathrm{~V}$ & Because// \\
58 & $\mathrm{M}$ & //Because they, because they took yes, ehm, five shots and have only scored four times. \\
59 & $\mathrm{~T}$ & Mhm. And then why does the fraction bar fit? \\
60 & $\mathrm{~K}$ & In the fraction// \\
61 & $\mathrm{M}$ & //Because it's four fifths. \\
62 & $\mathrm{~K}$ & In the fraction, it would be four fifths. \\
63 & $\mathrm{~T}$ & Okay. So on which justification do we agree? \\
64 & $\mathrm{M}$ & Because they had five// \\
65 & $\mathrm{~V}$ & //Because they scored four goals// \\
66 & $\mathrm{M}$ & Because they// \\
67 & $\mathrm{~K}$ & //took five shots and thereof only scored four. \\
\hline
\end{tabular}


Table 3 Episode with Makbule (M), Kiran (K), Vehbiya (V), and Teacher (T): Makbule (M) adopts "thereof" construction.

Person Utterances and gestures (translation from German to English; “//” indicates interruptions)

$70 \mathrm{M}$ reads her written answer: because they took five shots and thereof scored only 4.

$73 \mathrm{~T}$ So now the girls and the teachers. Where do we mark them?

$74 \mathrm{~V}$ The girls in the bar of tenths.

$75 \mathrm{~K}$ Eight tenths.

76 M So 8 out of, 8 out of 10 .

101 M So they have yes, ehm, they had 20 times to shoot, so could shoot 20 times. And they only, thereof they didn't score four.

Makbule (for details on conceptual development and a comparison of Makbule's and Kiran's inventories of vocabulary, see Wessel 2017).

Table 3 gives a condensed insight into Makbules reasoning initiated by Task 2 . The transcript is shortened to show how she flexibly applies both prepositional phrases (" out of _", and "_ thereof _"). Interestingly, she uses "out of" for the part-whole interpretation of the fraction (Turn 76) and "thereof" for relating the whole and the part in the soccer context.

Looking at both episodes holistically, we see how, in this group, the students are repeatedly reasoning about the relations between the three teams' rates (verbal register) and fraction bars as graphical representation (graphical register). In these processes of reasoning, the prepositional "_ thereof _" phrase seems to function as a lexical mean in the sense of language as a resource, because it stresses the conceptually relevant step of accounting for the number of attempts in order to fairly compare the three teams.

\section{Lexical demands for making structural relations within and between different registers explicit}

The next case of two students, Yagis (multilingual, low language proficiency) and Kibariye (multilingual, low language proficiency) from Group P (see episode in Table 4), is chosen for showing how students can be challenged lexically and conceptually when relating the three registers (graphical, symbolic, verbal) as well as when talking about structural relations within the graphical register. The discourse is initiated by the teacher aiming at clarification whether one of the teams scored better than the others (Turn 95).

Kibariye shows approval in Turn 96 so that the teacher draws attention to the fraction bar board (Turn 97). It is again Kibariye who states that the fraction bar was used for comparison (Turn 98). Yagis extends this thought by explaining that "It's the same" (Turn 100). "It" might refer to the colored part in the three fraction bars, and for each fraction bar, "it" is the same (see Fig. 4 for the picture of the fraction bar board). The teacher asks for clarification so that Yagis uses a gesture bound to the fraction bar board and states "this is all the same" (Turn 102). Still, Yagis' explanation remains implicit ("this"), and only in Turn 106 he extends his idea and becomes more explicit: He identifies a structural specificity of the fraction bar of twentieths (probably in comparison to the bar of fifths, and tenths): "Well, in the bar of twentieths, it is more - well smaller (...)." Although "it" is still not explicated, it becomes clear that Yagis 
Table 4 Episode with Kibariye (Ki), Yagis (Y), and Teacher (T) initiated by teacher moves to relate registers

\section{Person Utterances and gestures (translation from German to English; “//" indicates interruptions)}

$95 \mathrm{~T}$ And this means, now we have not yet finally decided if the teachers actually won the competition.

$96 \mathrm{Ki}$ Yes, they won.

$97 \mathrm{~T}$ Why did we draw this here in our fraction bar board?

$98 \mathrm{Ki} \mathrm{Hm}$, in order to compare.

$99 \mathrm{~T}$ Mhm. And what is//

$100 \mathrm{Y} / /$ It's the same.

$101 \mathrm{~T}$ What do you mean by that more precisely?

$102 \mathrm{Y}$ Indicates an imaginary vertical line: Well this is all the same.

$103 \mathrm{~T} \mathrm{Mh}$, when we take the ruler and put it vertically.

$104 \mathrm{Y}$ Yes and//

$105 \mathrm{Ki}$ [Incomprehensible]

$106 \mathrm{Y}$ Well in the bar of twentieths it is more - well smaller - well the pieces are smaller - the ones at the top are bigger.

[Teacher repeats what Yagis just said]

$109 \mathrm{~T}$ And what do you think, who has won?

$110 \mathrm{Y}$ All three.

$111 \mathrm{~T}$ And why?

$116 \mathrm{Y}$ They are all equal [hints at the three fraction bars of fifths, tenths, twentieths] only the pieces are just bigger for the boys and the girls.

$117 \mathrm{~T}$ Mh, what do the others think?

$118 \mathrm{Ki}$ But the teachers shot more often. And in the bar board there are only small pieces.

(...) Or did they all win because it is all the same in the bar board?

expresses a comparison: something being "more" and/or something being "smaller." He is more explicit in the next part of the sentence, when he says that "the pieces are smaller." Here, he refers to the pieces in the bar of twentieths compared with pieces in fraction bars "at the top" (Turn 106) of the fraction bar board, such as pieces in the bar of fifths.

Yagis uses this insight for reasoning why "all three" (Turn 110) won: "They are all equal - only the pieces are just bigger for the boys and the girls." (Turn 116; between

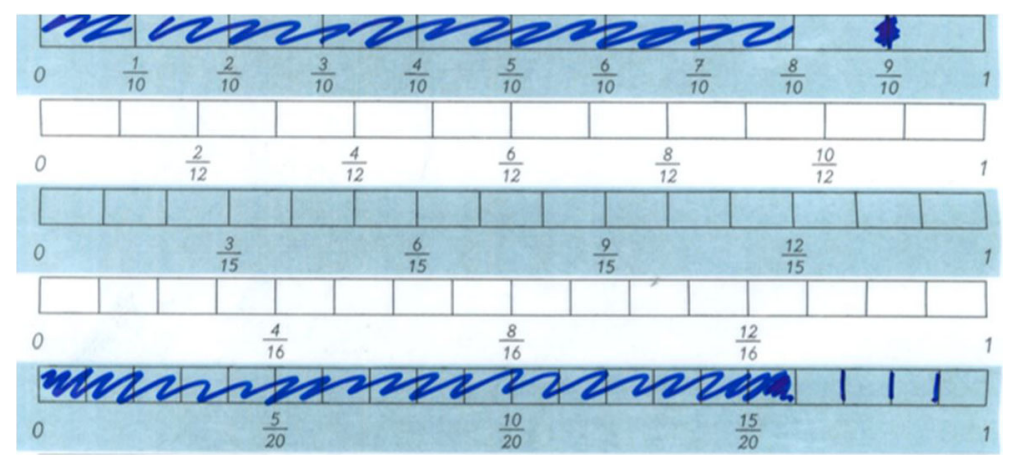

Fig. 4 Makbule colored $8 / 10$ and $16 / 20$ in the bar board 
110 and 116 one student starts a private discussion that the teacher solves in these turns). In Turn 106, we saw Yagis struggling between the notions of number (more) and size (smaller), a typical challenge on the conceptual and lexical learning pathway: Talking about the number of pieces in a fraction bar demands different vocabulary from talking about the sizes of pieces. This reveals a lexical demand of differentiating the number of pieces from the size of pieces (when equivalent fractions are investigated in the fraction bar). Yagis discovered an important general structural relation in the fraction bar board (within the graphical register): the pieces are getting smaller when you move down (see Fig. 4). Moreover, he also explains a structural relation between two registers (graphical and verbal): The equal length of the colored part is important for coming to the conclusion that none of the teams wins the competition.

So far, lexical demands appeared when students were challenged by making structural relations explicit. The case of Makbule now shows a successful learning process of overcoming this challenge by self-initiating structure-related lexical means. In contrast to this successful case, after that we also look at the case of Noel, Sarah, and their teacher who misses a chance to make structural relations explicit.

\section{The case of Makbule introducing structure-related lexical means for understanding equivalent fractions}

The learning processes in all analyzed groups have an important step on the conceptual learning pathway in common: they all accomplish empirical reasoning on the basis of observations drawn from the fraction bar board and come to the conclusion that no group scored better than another. The case of Makbule (multilingual, low language proficiency) is exceptional, because she self-initiates vocabulary from her individual everyday register (autonomous vocabulary) for making her structural reasoning explicit. Doing so, she also structurally relates four fifths, eight tenths, and sixteen twentieths in the graphical register (Table 5).

Table 5 Makbule (M) generates language for structural reasoning (with Teacher (T))

Turn Person Utterances and gestures (translation from German to English; “//” indicates interruptions)

$150 \mathrm{~T}$ So how can we identify equally good teams in the fraction bar board?

151 M They all similarly won. Because this bar [indicates the bar offifths] ... is this big [indicates the fifth fifth, which is not marked, and measures it with her thumb and index finger]. And for the bar of tenths it is ehm [holds the measured distance with her fingers and applies it to the two tenths on the right, which are not marked in the bar of tenths], one has to separate it in the middle one time. After that one has the same here [indicates $1 / 5$ and 2/10 in the bars of fifths and tenths, one after another]. And for the bar of twentieths one has to once again ... divide this small [indicates the bar of tenths, then the bar of twentieths]

$152 \mathrm{~T}$ Mhm. So how do you know if the teams are equally good?

153 M They have all shot similarly, only the bars look different.

$180 \mathrm{M} \quad$ [Reads out her written answer for Task 3] So nobody has won, because the bars are all equally big. The boys have $4 / 5$ and the bar is normal big. But when you look ... for the ... for the girls, well they have $8 / 10$ and the bar has to be separated in the middle. And for the teachers the bar has to be separated in the middle and then once again separated in the middle. 
Makbule identifies the structural relations in the fraction bar board and self-initiates the phrase "to separate in the middle" to talk about refining the division in the bar of fifths and tenths from her autonomous vocabulary (Turn 151): "And for the bar of tenths it is, ehm, one has to separate it in the middle one time." Here, she refers to the bar of fifths and describes how one has to divide each fifth into halves in order to generate tenths (see Fig. 4).

When answering Task 3 (Turn 180), she uses the phrase "separating in the middle" for generating twentieths. Instead of using the verb "to quarter," she verbalizes the process of halving twice (dividing fifths into halves gives tenths, dividing tenths into halves gives twentieths). Makbule's self-initiated vocabulary is rather informal ("normal big," "to separate in the middle," "divide small") but captures the structural relations that constitute the process of refining.

While some students do not overcome empirical reasoning on the basis of the fraction bars' equal length, Makbule observes the differences in the fraction bars' structures and takes on a structural view behind the empirically found phenomenon of equal length: "They have all shot similarly, only the bars look different" (Turn 153). Moreover, she is also able to make explicit how the bar of twentieths structurally relates to the bar of fifths and tenths.

\section{The case of Noel, Sarah, and their teacher leaving structural relations implicit}

Contrary to the previous case, in the group with Noel and Sarah (both monolingual, high language proficiency), talking about structural relations within and between the fraction bars plays a less prominent role. The case has been chosen to exemplify how a teacher misses a chance to talk about structural relations explicitly.

When discussing Task 1 (see Table 6), Turns 41-44 indicate moments of structural reasoning. Sarah, when reflecting on the unequal number of attempts for the different groups, carries out a thought experiment: What if the teachers also only had five attempts like the boys? (Turn 43, "the teachers, if they had had five"). Noel concludes that in this case the teachers "would have also only missed one" (Turn 44).

Table 6 Noel (N) and Sarah (S) carrying out a thought experiment

\begin{tabular}{|c|c|c|}
\hline Turn & Person & Utterances and gestures (translation from German to English; " “/p" indicates interruptions) \\
\hline 41 & $\mathrm{~S}$ & But the boys had fewer chances. They had only five chances. \\
\hline 42 & $\mathrm{~N}$ & But missed one. \\
\hline 43 & $\mathrm{~S}$ & Yes, they missed one. The teachers, if they had had five, ehm// \\
\hline 44 & $\mathrm{~N}$ & //they would have also only missed one. \\
\hline \multicolumn{3}{|l|}{$\ldots$} \\
\hline 117 & $\mathrm{~T}$ & All teams have won, mh [expresses consent] \\
\hline 108 & $\mathrm{~N}$ & $\begin{array}{l}\text { Because if they [refers to the girls and the teachers] had had } \\
\text { also only five, they all would have another score as well. }\end{array}$ \\
\hline 109 & $\mathrm{~T}$ & $\begin{array}{l}\text { What you just said ... Into this bar of tenths one can also } \\
\text { see the bar of fifths, right? [indicates bar of tenths and } \\
\text { fifths in the fraction bar board] }\end{array}$ \\
\hline
\end{tabular}


When working on Task 2, Noel comes back to this more structural view (Turn 108). He simplifies from twentieths and tenths to fifths and draws the conclusion that in this case "they all would have another score as well." This notion is taken up by the teacher in a rather vague way by rephrasing: "Into this bar of tenths one can also see the bar of fifths, right?" (Turn 109). At this moment, the teacher seems to aim at the structural relation between the fraction bars of fifths and tenths. However, the students are not asked to further explicate the relations between the different registers (results of the girls, results of the boys, and graphical representations in the respective fraction bars). Additionally, they do not get further lexical support from the teacher for talking about the changes in the graphical register when simplifying from tenths to fifths (e.g., vocabulary offers such as "two pieces in the bar of tenths become one piece in the bar of fifths"). In summary, in this group's learning process, the structural relations between the graphical and verbal registers stay rather implicit.

A concluding discussion of the insights gained from comparing and contrasting the presented cases is carried out in the "Discussion" section. Before that, research question Q2 will be explored in the next section.

\section{Quantitative comparisons of self-initiated and triggered vocabulary}

In this section, research question Q2 is in focus (To what extent do students self-initiate or take up lexical means from teaching material, the teacher, or peers in local processes initiated by the presented learning opportunities?). A quantitative summary of the results of the trace analyses is given. For this summary, the transcribed small-group learning processes initiated in two different lessons of the overarching intervention build the database $(n=16$ students for lesson 2, and $n=17$ for lesson 1; in total $298 \mathrm{~min}$ of analyzed video data).

Table 7 presents the absolute numbers and average rates for the four categories "selfinitiation" (1), "material as trigger" (2), "teacher as trigger" (3), and "peers as trigger"

Table 7 Quantitative results of trace analysis

\begin{tabular}{|c|c|c|c|c|c|c|c|}
\hline & & & \multicolumn{4}{|l|}{ Category } & \multirow[t]{2}{*}{ Total } \\
\hline & & & $\begin{array}{l}\text { Self- } \\
\text { initiated }\end{array}$ & $\begin{array}{l}\text { Teaching } \\
\text { material } \\
\text { as trigger }\end{array}$ & $\begin{array}{l}\text { Teacher } \\
\text { as } \\
\text { trigger }\end{array}$ & $\begin{array}{l}\text { Peer } \\
\text { as } \\
\text { trigger }\end{array}$ & \\
\hline \multirow[t]{6}{*}{ Mode } & \multirow[t]{3}{*}{ Oral } & Inventoried number of lexical means & 493 & 89 & 96 & 220 & 898 \\
\hline & & Expected number of lexical means & 472.2 & 91.6 & 121.3 & 212.9 & 898 \\
\hline & & $\begin{array}{l}\text { Average rates in } \% \text { : } \\
\text { Inventoried number of lexical means in } \\
\text { category (1) - (4) divided by the total } \\
\text { number of inventoried lexical means }\end{array}$ & $54.9 \%$ & $9.9 \%$ & $10.7 \%$ & $24.5 \%$ & $100 \%$ \\
\hline & \multirow[t]{3}{*}{ Written } & Inventoried number of lexical means & 239 & 53 & 92 & 110 & 494 \\
\hline & & Expected number of lexical means & 259.8 & 50.4 & 66.7 & 117.1 & 494 \\
\hline & & $\begin{array}{l}\text { Average rates in } \% \text { : } \\
\text { Inventoried number of lexical means in } \\
\text { category (1) - (4) divided by the total } \\
\text { number of inventoried lexical means }\end{array}$ & $48.4 \%$ & $10.7 \%$ & $18.6 \%$ & $22.3 \%$ & $100 \%$ \\
\hline
\end{tabular}


(4) across all students in the sample and for the modes "oral (o)" and "written (w)" language use (see Steps $2 \mathrm{~b}$ and $2 \mathrm{c}$ of trace analysis).

With a chi-square test, the expected numbers of lexical means in the four categories have been calculated and compared with the inventoried (observed) numbers of lexical means (see Table 7). Testing the $\mathrm{N}_{0}$ hypothesis of "mode" and "category" not being associated provides rejection of independence (chi-squared $=18.304, d f=3, p=$ $0.0003807<0.05)$. The test results provide a significant relationship between the variables "mode" and "category": the use of a lexical mean as self-initiated or being triggered by others seems to relate to the mode of use (oral or written). In consequence, the inventoried numbers of lexical means and average rates in percent can be interpreted more closely.

In both modes, the deviation of observed lexical means and expected lexical means is rather high for the categories "self-initiation" and "teacher as trigger" (see absolute values in italics in Table 7). Comparing the rates for oral and written mode, a slight decrease in self-initiation (from $55 \%$ (o) to $49 \%$ (w)) happens together with an increase of lexical means triggered by the teacher (from $11 \%$ (o) to $19 \%(w)$ ). An explanation for the latter might be the structure of the tasks of the learning opportunities: Writing down one's own reasoning in both analyzed lessons happens at the end of the analyzed learning opportunities. There might be a tendency of the students to rely more on the teacher as a lexical role model over the course of a lesson. This could explain why the number of inventoried lexical means in this category ("teacher as trigger") and in written mode lies above the expected number of lexical means (while in oral mode the number of inventoried lexical means is below the expected number of lexical means).

For further interpretation of the category "self-initiation," and thus for an interpretation of the students' autonomous vocabulary, the coding procedure has to be taken into account (see the "Qualitative and quantitative methods for data analysis" section): "self-initiation" refers to lexical means that have been identified as self-initiated within the analyzed excerpts of two lessons of the overarching intervention. For both, oral and written mode, "self-initiation" is the most frequently coded category. Of course, these numbers have to be interpreted in light of the methodological restrictions. With these methodological limitations in mind, the quantitative summary shows that task- and concept-specific lexical means are retrieved from students' autonomous vocabularies (self-initiated lexical means) and the groups' collective vocabularies (lexical means triggered by teacher, material, peers) at almost comparable rates (roughly $50 \%$ each).

\section{Discussion}

The quantitative summary of the lexical trace analyses of students' lexical means across two lessons shows the following patterns: while we see high rates of self-initiation for the inventoried lexical means (55\% in oral, $48 \%$ in written mode), another roughly $40 \%$ ( $36 \%$ in oral, $41 \%$ in written mode) of the inventoried vocabulary is triggered by teachers or peers. This finding underlines the importance of micro-scaffolding on the lexical level (for the notion of micro-scaffolding, see Gibbons 2002) not only with respect to teachers but also in peer-to-peer situations. The case of Kiran in the "Specifying students' language demands on the basis of lexical trace analyses" section exemplified how one of the students introduces vocabulary into a group's collective 
vocabulary and how another student in the group adopts the vocabulary for stressing a conceptually relevant relation. Moreover, the quantitative results show that students take up lexical means from the teaching material at rather low rates in these specific learning processes being analyzed.

For exploring research question Q1, qualitative in-depth analyses have been carried out. It turned out that the students use a variety of lexical means and introduce their own meaning-related vocabulary into the group's collective vocabulary for making structural relations explicit. This might be one of the reasons why few lexical means have been taken up from the teaching material. The cases of Yagis and Makbule showed how students with low language proficiency rely on their rather informal lexical resources from their everyday language resources (Planas and Civil 2013). Drawing further on the concept of language as a resource for the inspected learning opportunities, it is concluded that the lexical means "refine" and "coarsen" (offered in the teaching material) did not yet function as a resource and needed to be unfolded. Additionally, some of the lexical means introduced by teachers (e.g., "see a finer division in the bar" in the case of Noel's and Sarah's teacher) did not meet the identified conceptual and lexical demands of students. Extending the perspective from students' learning processes to teachers' lexical (scaffolding) moves, the empirical insights point to the topic-specific knowledge demands imposed on teachers when teaching with multiple representations. Employing appropriate language when using representations is distilled as one task in the framework by Mitchell et al. (2014) for teaching with representations. An understanding of appropriate language, however, needs topic-specific research that combines methodological approaches that allow for conceptual and linguistic insights like the previous ones and those summarized in the following.

Both, Makbule and Yagis, introduced more informal vocabulary (such as "to separate in the middle," and "this one piece becomes two" by Makbule; "only the pieces are just bigger" by Yagis) for unfolding the meaning behind the process of refining or coarsening the inner structure in a fraction bar. Relying on the notion of structure-related lexical means from the everyday language and school academic language, we see how this vocabulary serves as a resource for developing structural understanding. The empirical analyses thus contribute to topic-specifically identifying the lexical demands of structural reasoning why two rates are equally good (consequently why two fractions are equivalent) initiated by a teaching design that draws upon activities of relating multiple registers and representations.

The in-depth analyses of the full data set further show that the intended structural reasoning for equivalence was not initiated similarly deeply in all groups. At a continuum between empirical reasoning (based on observations at the fraction bar board, e.g., no team wins because the fraction bars are all equally long) and formal reasoning (independent from the context and the graphical representation), two kinds of structural reasoning have been activated (not to be seen as hierarchical order):

(a) Structural reasoning on the basis of the given context situation as a mental model: When you have x as many attempts you also have to score x times as many goals to be as good. Froma lexical perspective, this kind of reasoning demands context-related lexical means. 
(b) Structural reasoning on the basis of the inner structure of the fraction bars as a mental model: The colored parts of the fraction bars are equal, but the division is either refined (more parts in a whole, each piece gets smaller) or coarsened (less parts in a whole, each piece gets bigger). From a lexical perspective, this kind of reasoning demands structure-related lexical means.

Different kinds of reasoning go along with certain lexical demands (rather contextrelated in (a), rather structure-related in (b)). The specification and structuring of the relevant lexical means revealed that in the analyzed learning opportunities (see Fig. 2), the lexical offers rather relate to empirical reasoning and structural reasoning on the basis of the given context. Lexical means for structural reasoning on the basis of the inner structure of the fraction bars as a mental model (e.g., the verbs "refine" and "coarsen" to talk about the structural relations) stay rather implicit. As a consequence, in learning processes in which structural relations in the fraction bar board have been made explicit, the relevant lexical means are student- or teacher-generated.

As a contribution for local theory building as one important aim of design research, the trace analyses and lexical inventories structured along the conceptual learning pathways lead to further refining the model of representations and registers (Fig. 5). On the verbal academic school register level, the basic meaning-related vocabulary needs differentiation into the two finer sub-categories: meaning-related vocabulary referring to contexts and meaning-related vocabulary referring to structure (in Fig. 5 as context-related and structure-related vocabulary). In contrast, the formal vocabulary is independent of context and graphical representations.

With respect to design principles for initiating lexical learning processes, this study shows that in the design of activities, both kinds of vocabulary (context- and structurerelated) seem important for developing conceptual understanding. This is why planning content- and language-integrated lesson designs requires a careful analysis of the relevant lexical means with respect to both kinds of meaning-related vocabulary.

Limitations of the study arise due to the fact that the learning processes of only a small sample of students working on very particular learning opportunities have been analyzed. Additionally, research on language and language learning like it is carried out in this study highly depends on the language of teaching and instruction, which in this case was German. Although issues will always remain on the extent to which the findings are transferrable to other language contexts, the study provides relevant theoretical and empirical contributions to the field of language-responsive mathematics teaching and learning.

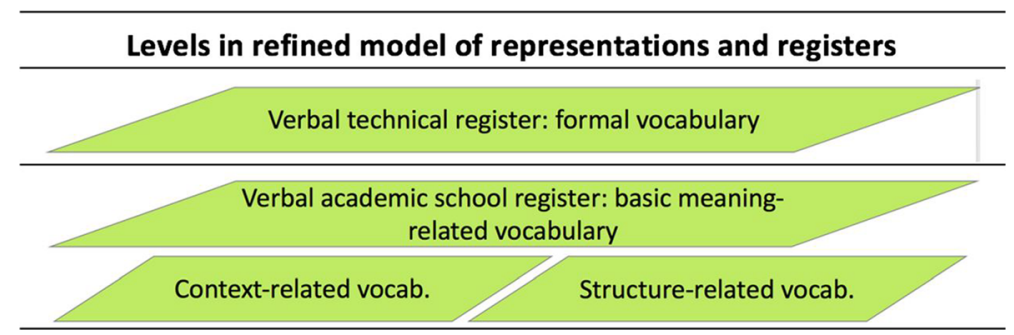

Fig. 5 Context- and structure-related vocabulary as part of the basic meaning-related vocabulary 
Funding Information The research project MESUT (Developing conceptual understanding by language support: Differential effects of language- and content-integrated approaches) is funded by the German Research Foundation (DFG; grant PR 662/14-1 to S. Prediger). The author conducted this research with Susanne Prediger and Kirstin Erath.

\section{Appendix}

Table 8 Consolidated inventory of lexical means for learning opportunities towards equivalent fractions

Lexical means in German

Schuss/Schüsse

... Schüsse geworfen

... Schüsse gehabt

schießen/geschossen

... mal schießen/... Mal geschossen

gleich geschossen

besser geschossen

verschossen

weniger geschossen

mehrere Tore geschossen

mehrmals schießen

oft schießen

... Mal versucht

Treffer

getroffen

... mal getroffen

besser getroffen

am meisten getroffen

öfters getroffen

.... Mal werfen

mehr getroffen als

nicht getroffen

... Mal nicht getroffen

... Mal daneben getroffen

... Mal nicht geschafft

nicht so gut getroffen

weniger getroffen

alles getroffen

verfehlt

in ... Schüssen ... mal getroffen

am wenigsten Schüsse

doppelt so viele Schüsse

doppelt so oft schießen

doppelt so oft treffen

verdoppelt

gleich oft getroffen
English translations of lexical means

attempt/attempts
thrown ... attempts
had ... attempts
to shoot/shot
shot ... times
equally shot
shot better
failed
shot less
scored several goals
to shoot several times
to shoot often
tried ... many times
goals
scored
scored ... many times
scored better
scored most
scored more often
to throw ... many times
score more than
not scored
not scored ... many times
failed ... many times
did not make it ... many times
not scored as well as ...
scored less
scored all
missed
scored... times in ... attempts
least trials
twice as many trials


Table 8 (continued)

Lexical means in German

so oft geschossen

insgesamt geschossen

Tore machen

ein Tor nicht gemacht

Anzahl

Anzahl der Treffer

Anzahl der Versuche

Anzahl der geschossenen Treffer

Anzahl der nicht getroffenen

höhere Anzahl

wenig

$\mathrm{mehr} / \mathrm{mehr}$ als

besser/besser als

am besten

gewinnen/haben gewonnen

Verlieren/haben verloren

... davon ...

... von ...

Gleichstand

unentschieden

weil

deswegen

wenn

wenn ... dann ...

desto mehr ... desto öfter

genauso

genauso groß

genauso lang

fast gleich

gleich

gleich groß

gleich lang

gleich viel

gleich gut

gleich gut wie

genauso gut wie

das Gleiche

alles auf einer Linie

doppelte Menge

doppelte Fehler

Fehler

Fehltreffer

Chance

Zahl, die sie insgesamt geschossen haben

... Mal Chance zum schießen

mehr Chancen
English translations of lexical means

to shoot this often

shots in total

make goals

not made a goal

number

number of goals

number of attempts

number of shot goals

number of not scored

higher number

little

more/more than

better/better than

the best

to win/won

to lose/lost

... thereof ...

... out of ...

tie

draw

because

therefore

when

if ... then ...

the more ... the more often

equal

just as bit

just as long

almost equal

similar

similar big

similar long

the same number of

equally good/well

equally good/well as

just as good as

the same

all in one line

double the amount

double the mistake

mistake

fail

chance

number of all attempts in total

... times the chance to shoot

more chances 
Table 8 (continued)

\begin{tabular}{|c|c|}
\hline Lexical means in German & English translations of lexical means \\
\hline in der Mitte teilen & to divide in the middle \\
\hline in der Mitte getrennt & separated in the middle \\
\hline getrennt & separated \\
\hline gut gespielt & played well \\
\hline passt zu & fits to \\
\hline klein teilen & divide small \\
\hline (so) groß & (this) big \\
\hline kleiner & smaller \\
\hline größer & bigger \\
\hline Bruch & fraction \\
\hline das Ganze & the whole \\
\hline Stücke/Kästchen & pieces \\
\hline kürzen & simplify \\
\hline zurückrechnet & to calculate back \\
\hline erweitern & expand \\
\hline auf gleichen Nenner bringen & find the same numerator \\
\hline Prozent & percent \\
\hline mehr Prozent & more percent \\
\hline das Doppelte & double \\
\hline unfair & unfair \\
\hline (Bruch-) Streifentafel & (fraction) bar board \\
\hline Streifen & strip \\
\hline Balken & bar \\
\hline Striche & lines \\
\hline der markierte Teil & the colored part \\
\hline einteilen & to partition \\
\hline geteilt & divided \\
\hline wie viel/wie viele & how much/how many \\
\hline insgesamt & in total \\
\hline insgesamt alles & in total all \\
\hline näher zum Ergebnis & closer to the result \\
\hline weniger Versuche & less attempts \\
\hline Einen, der fehlt & one that is missing \\
\hline Länge & length \\
\hline vergleichen & to compare \\
\hline Verhältnis & ratio \\
\hline pro Person & per person \\
\hline
\end{tabular}

Open Access This article is distributed under the terms of the Creative Commons Attribution 4.0 International License (http://creativecommons.org/licenses/by/4.0/), which permits unrestricted use, distribution, and reproduction in any medium, provided you give appropriate credit to the original author(s) and the source, provide a link to the Creative Commons license, and indicate if changes were made. 


\section{References}

Aitchison, J. (2003). Words in the mind: an introduction to the mental lexicon (3rd ed.). Malden: Blackwell Publishing.

Aksu, M. (1997). Student performance in dealing with fractions. Journal of Educational Research, 90(6), $375-380$.

Bailey, A. L. (Ed.). (2007). The language demands of school: putting academic English to the test. New Haven: Yale.

Balacheff, N. (1988). Aspects of proof in pupils' practice of school mathematics. In D. Pimm (Ed.), Mathematics, teachers and children (pp. 216-235). London: Hodder and Stoughton.

Bruner, J. S. (1967). Toward a theory of instruction. Cambridge: Harvard University Press.

Clarkson, P. (2009). Mathematics teaching in Australian multilingual classrooms. In R. Barwell (Ed.), Multilingualism in mathematics classrooms - global perspectives (pp. 145-160). Bristol: Multilingual Matters.

Cobb, P., Confrey, J., diSessa, A., Lehrer, R., \& Schauble, L. (2003). Design experiments in educational research. Educational Researcher, 32(1), 9-13. https://doi.org/10.3102/0013189x032001009.

Cramer, K., Behr, M., Post, T., \& Lesh, R. (1997). Rational number project: Fraction lessons for the middle grades - level 1. Dubuque Iowa: Kendall/Hunt Publishing.

Donelly, W. B., \& Roe, C. J. (2010). Using sentence frames to develop academic vocabulary for English learners. The Reading Teacher, 64(2), 131-136.

Duval, R. (2006). A cognitive analysis of problems of comprehension in a learning of mathematics. Educational Studies in Mathematics, 61(1-2), 103-131.

Fisher, D., \& Frey, N. (2008). Word wise and content rich, grades 7-12: five essential steps to teaching academic vocabulary. Portsmouth, NH: Heinemann.

Gibbons, P. (2002). Scaffolding language, scaffolding learning. In Teaching second language learners in the mainstream classroom. Portsmouth: Heinemann.

Gravemeijer, K., \& Cobb, P. (2006). Design research from the learning design perspective. In J. van den Akker et al. (Eds.), Educational design research (pp. 45-85). London: Routledge.

Grundler, E. (2009). Argumentieren lernen - die Bedeutung der Lexik. [The learning of arguing - the relevance of lexis.]. In M. Krelle (Ed.), Sprechen und Kommunizieren: Entwicklungsperspektiven, Diagnosemöglichkeiten und Lernszenarien in Deutschunterricht und Deutschdidaktik (pp. 82-98). Baltmannsweiler: Schneider-Verlag Hohengehren.

Haag, N., Heppt, B., Stanat, P., Kuhl, P., \& Pant, H. A. (2013). Second language learners' performance in mathematics: disentangling the effects of academic language features. Learning and Instruction, 28(0), 24-34. https://doi.org/10.1016/j.learninstruc.2013.04.001.

Halliday, M. A. K. (1978). Language as social semiotic: the social interpretation of language and meaning. Maryland: University Park Press.

Heinze, A., Reiss, K., Rudolph-Albert, F., Herwartz-Emden, L., \& Braun, C. (2009). The development of mathematical competence of migrant children in German primary schools. In M. Tzekaki, M. Kaldimidou, \& H. Sakonidis (Eds.), Proceedings of the 33rd PME (Vol. 3, pp. 145-152). Thessaloniki: PME.

Heller, V., \& Morek, M. (2015). Academic discourse as situated practice: an introduction. Linguistics \& Education, 28(31), 174-186. https://doi.org/10.1016/j.linged.2014.01.008.

Hirsch, E. D. (2003). Reading comprehension requires knowledge - of words and the world. Scientific insights into the fourth-grade slump and the nation's stagnant comprehension scores. American Educator, 4(1), $10-44$.

Kilpatrick, J., Swafford, J., \& Findell, B. (2001). Adding it up. Helping children learn mathematics. Washington, DC: National Academy Press.

Lamon, S. J. (2007). Rational numbers and proportional reasoning: toward a theoretical framework for research. In F. Lester (Ed.), Second handbook of research on mathematics teaching and learning (pp. 629-668). Charlotte, NC: Information Age Publishing.

Lesh, R. (1979). Mathematical learning disabilities. In R. Lesh et al. (Eds.), Applied mathematical problem solving (pp. 111-180). Columbus: $\mathrm{OH}$.

Mitchell, R., Charalambous, C. Y., \& Hill, H. C. (2014). Examining the task and knowledge demands needed to teach with representations. Journal of Mathematics Teacher Education, 17(1), 37-60.

Moschkovich, J. N. (2013). Principles and guidelines for equitable mathematics teaching practices and materials for English language learners. Journal of Urban Mathematics Education, 6(1), 45-57. 
Moschkovich, J. N. (2015). Academic literacy in mathematics for English learners. The Journal of Mathematical Behavior, 40(A), 43-62.

Niederhaus, C., Pöhler, B., \& Prediger, S. (2016). Relevante Sprachmittel für mathematische Textaufgaben Korpuslinguistische Annäherung am Beispiel Prozentrechnung. [Relevant lexical means for mathematical word problems - Corpus linguistic approach using the example of percentages.]. In E. Tschirner, O. Bärenfänger, \& J. Möhring (Eds.), Kompetenzprofile Deutsch als fremde Bildungssprache: Das Spannungsfeld von Fachwissen, sprachlicher Kompetenz, Diagnostik und Didaktik (pp. 135-162). Stauffenburg: Tübingen.

O'Halloran, K. (2015). The language of learning mathematics: a multimodal perspective. The Journal of Mathematical Behavior., 40(Part A), 63-74.

OECD. (2007). Science competencies for tomorrow's world (PISA 06) (Vol. 2). Paris: OECD.

Orton, A. (1987). Learning mathematics: issues, theory, and classroom practice. London: Cassell Education.

Pimm, D. (1987). Speaking mathematically. Communication in mathematics classrooms. London, United Kingdom / New York, NY: Routledge.

Planas, N., \& Civil, M. (2013). Language-as-resource and language-as-political: tensions in the bilingual mathematics classroom. Mathematics Education Research Journal, 25(3), 361-378 https://doi. org/10.1007/s13394-013-0075-6.

Pöhler, B., \& Prediger, S. (2015). Intertwining lexical and conceptual learning trajectories - a design research study on dual macro-scaffolding towards percentages. Eurasia Journal of Mathematics, Science \& Technology Education, 11(6), 1697-1722.

Prediger, S. (2008). The relevance of didactic categories for analysing obstacles in conceptual change: revisiting the case of multiplication of fractions. Learning and Instruction, 18(1), 3-17.

Prediger, S. (2011a). Why Johnny can't apply multiplication: revisiting the choice of operations with fractions. International Electronic Journal of Mathematics Education, 6(2), 65-88.

Prediger, S. (2011b). Anknüpfen, Konfrontieren, Gegenüberstellen. Strategien zur Weiterarbeit mit individuellen Vorstellungen am Beispiel relativer Häufigkeiten. [Linking, confronting, contrasting. Strategies for working with individual mental models of relative frequency.]. Praxis der Mathematik in der Schule, 53(40), 8-13.

Prediger, S. (2011c). Vorstellungsentwicklungsprozesse initiieren und untersuchen. Einblicke in einen Forschungsansatz am Beispiel Vergleich und Gleichwertigkeit von Brüchen in der Streifentafel. [Initiating and analysing learning processes. Insights into a research approach using the example of fraction comparison and equivalence in the fraction bar board.]. Der Mathematikunterricht, 57(3), 5-14.

Prediger, S. (2013). Focusing structural relations in the bar board - a design research study for fostering all students' conceptual understanding of fractions. In B. Ubuz, C. Haser, \& M. A. Mariotti (Eds.), Proceedings of the 8th Congress of the European Society for Research in Mathematics Education (pp. 343-352). Ankara: METU University.

Prediger, S., \& Wessel, L. (2013). Fostering German-language learners' constructions of meanings for fractions - Design and effects of a language- and mathematics-integrated intervention. Mathematics Education Research Journal, 25(3), 435-456. https://doi.org/10.1007/s13394-013-0079-2.

Prediger, S., \& Pöhler, B. (2015). The interplay of micro- and macro-scaffolding: an empirical reconstruction for the case of an intervention on percentages. ZDM Mathematics Education, 47(7), 1179-1194.

Prediger, S., \& Zindel, C. (2017). School academic language demands for understanding functional relationships: a design research project on the role of language in reading and learning. Eurasia Journal of Mathematics, Science and Technology Education, 13(7b), 4157-4188. https://doi.org/10.12973 /eurasia.2017.00804a.

Prediger, S., Gravemeijer, K., \& Confrey, J. (2015a). Design research with a focus on learning processes - an overview on achievements and challenges. ZDM Mathematics Education, 47(6), 877-891.

Prediger, S., Wilhelm, N., Büchter, A., Gürsoy, E., \& Benholz, C. (2015b). Language proficiency and mathematics achievement - empirical study of language-induced obstacles in a high stakes test, the central exam ZP10. English translation of the article: Sprachkompetenz und Mathematikleistung Empirische Untersuchung sprachlich bedingter Hürden in den Zentralen Prüfungen 10. Journal für Mathematik-Didaktik, 36(1), 77-104. https://doi.org/10.1007/s13138-015-0074-0.EnglishDOI10.1007 /s13138-018-0126-3.

Quasthoff, U. (2012). Globale und lokale Praktiken in unterschiedlichen diskursiven Genre. Wie lösen L2Sprecher globale Anforderungen bei eingeschränkter sprachstruktureller Kompetenz im Deutschen? [Global and lokal practices in different discursive genres. How do L2 speaker with limited German structural language proficiency solve global challenges?]. In H. Roll \& A. Schilling (Eds.), Mehrsprachiges Handeln im Fokus von Linguistik und Didaktik (pp. 47-65). Universitätsverlag RheinRuhr: Duisburg. 
Riccomini, P. J., Smith, G. W., Hughes, E. M., \& Fries, K. M. (2015). The language of mathematics: the importance of teaching and learning mathematical vocabulary. Reading \& Writing Quarterly, 31(3), 235252. https://doi.org/10.1080/10573569.2015.1030995.

Schleppegrell, M. J. (2004). The language of schooling: a functional linguistics perspective. Mahwah: Lawrence Erlbaum.

Schleppegrell, M. (2007). The linguistic challenges of mathematics teaching and learning: a research review. Reading \& Writing Quarterly, 23, 139-159. https://doi.org/10.1080/10573560601158461.

Schüler-Meyer, A., Prediger, S., Kuzu, T., Wessel, L., \&amp; Redder, A. (2019). Is formal language proficiency in the home language required to profit from a bilingual teaching intervention in mathematics? A mixed methods study on fostering multilingual students' conceptual understanding. International Journal of Science and Mathematics Education, 17(2), 317-339. https://doi.org/10.1007/s10763-0179857-8.

Schwarzkopf, R. (2003). Begründungen und neues Wissen: Die Spanne zwischen empirischen und strukturellen Argumenten in mathematischen Lernprozessen der Grundschule. [Reasoning and new knowledge: The continuum between empirical and structural arguments in mathematical learning processes in primary school.]. Journal für Mathematik-Didaktik, 24(3), 211-235. https://doi.org/10.1007 /BF03338982.

Secada, W. (1992). Race, ethnicity, social class, language and achievement in mathematics. In D. A. Grouws (Ed.), Handbook of research on mathematics teaching and learning (pp. 623-660). New York, NY: Macmillan.

Short, D. J. (2017). How to integrate content and language learning effectively for English language learners. Eurasia Journal of Mathematics, Science and Technology Education, 13(7b), 4237-4260. https://doi. org/10.12973/eurasia.2017.00806a.

Steinbring, H. (1994). Die Verwendung strukturierter Diagramme im Arithmetikunterricht der Grundschule. Zum Unterschied zwischen empirischer und theoretischer Mehrdeutigkeit mathematischer Zeichen. [The use of structured diagrams in primary school arithmetics. On the difference between empirical and theoretical ambiguity of mathematical signs.]. Mathematische Unterrichtspraxis, 4, 7-19.

Steinbring, H. (2005). The construction of new mathematical knowledge in classroom interaction - an epistemological perspective. Berlin / New York: Springer.

Thompson, D., \& Rubenstein, R. (2000). Learning mathematics vocabulary: potential pitfalls and instructional strategies. The Mathematics Teachers, 93(7), 568-574.

Ufer, S., Reiss, K., \& Mehringer, V. (2013). Sprachstand, soziale Herkunft und Bilingualität: Effekte auf Facetten mathematischer Kompetenz. [Language proficiency, social background, and bilingualism: effects on facets of mathematical proficiency.]. In M. Becker-Mrotzek, K. Schramm, E. Thürmann, \& H. J. Vollmer (Eds.), Sprache im Fach - Sprachlichkeit und fachliches Lernen (pp. 167-184). Münster: Waxmann.

Vygotsky, L. S. (1978). Mind in society. The development of higher psychological processes. Cambridge: Harvard University Press.

Wessel, L. (2015). Fach- und sprachintegrierte Förderung durch Darstellungsvernetzung und Scaffolding. Ein Entwicklungsforschungsprojekt zum Anteilbegriff. [Content- and language integrated teaching by relating registers and scaffolding. A design research study on understanding fractions.] Heidelberg: Springer Spektrum.

Wessel, L. (2017). How do students develop lexical means for understanding the concept of relative frequency? Empirical insights on the basis of trace analyses. In Dooley, T., \&amp; Gueudet, G. (Eds.), Proceedings of the Tenth Congress of the European Society for Research in Mathematics Education (CERME10, February 1-5, 2017) (pp. 1388-1395). Dublin, Ireland: DCU Institute of Education and ERME.

Zahner, W., Velazquez, G., Moschkovich, J. N., Vahey, P., \& Lara-Meloy, T. (2012). Mathematics teaching practices with technology that support conceptual understanding for Latino/a students. The Journal of Mathematical Behavior, 31, 431-446. https://doi.org/10.1016/j.jmathb.2012.06.002.

Publisher's note Springer Nature remains neutral with regard to jurisdictional claims in published maps and institutional affiliations. 